www.jmscr.igmpublication.org

Impact Factor (SJIF): 6.379

Index Copernicus Value: 79.54

ISSN (e)-2347-176x ISSN (p) 2455-0450

crossrefDOI: https://dx.doi.org/10.18535/jmscr/v6i9.81

\title{
Leucocyte Adhesion Deficiency Type -1 Presenting as a Severe Anal Ulceration-A Case Report
}

\author{
Authors

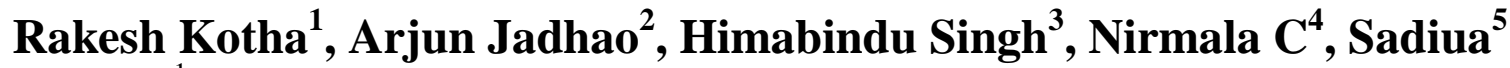 \\ ${ }^{1}$ MD DM (neonatology JIPMER), Asst. Prof. Neonatology at Niloufer \\ Email:dr.rakeshkotha@gmail.com \\ ${ }^{2}$ MBBS DCH Fellowship in Neonatology, Jr Consultant at Navodaya Hospitals \\ Email: arjunmedicine@gmail.com \\ ${ }^{3}$ Prof., of Neonatology at Niloufer \\ Email:dr.himabindusingh@gmail.com \\ ${ }^{4}$ Professor Neonatology Niloufer \\ ${ }^{5} \mathrm{Sr}$ Neonatology Niloufer
}

\begin{abstract}
Leucocyte adhesion deficiency is a rare AR inherited primary immunodeficiency disorder with neutrophila due to lack of leukocyte recruitment at the site of infection. LAD type I results from lack of expression of leukocyte $\beta 2$ integrin's (CD 11 and CD 18) a trans membrane signal transfer proteins that are essential for leukocyte adhesion and chemo taxis. It clinically presents as delayed umbilical cord separation, no pus formation and uncontrolled infections. In severe form where expression is $<1 \%$ prognosis was poor usually they succumb to prone life-threatening infection within two years.
\end{abstract}

\section{Background}

As such neonate is physiologically immunodeficient particularly cell mediated immunity, some primary immunodeficiency disorders will clinically present at newborn period only. An early Clinical eye on immunodeficiency disorders will lead to early diagnosis and good prognosis. LAD I results from lack of cell surface expression of $\beta 2$ integrins (CD 11 and CD 18) due to mutation in ITGB2 gene that are essential for adhesion and chemo taxis.

\section{Case Report}

10-day-old term male AGA referred here from pvt hospital. Baby born to Gravida 2 mother under third degree consanguineous marriage by LSCS i/v/o previous section and cried immediately after birth. Family history was nothing significant. Baby on DBF referred in view of abdominal distention. Baby admitted and investigated for abdominal distention. At the time of admission baby had mild anal excoriation during 5 days it progressed to severe ulceration. Due to unusual progression of wound, persistence of umbilical cord and peripheral neutrophilia investigated in 
line of LAD. Investigations showed $\mathrm{Hb} 12.79 \%$ WBC 87,900 p68\% L11\% M6\% platelets 1.3 lakhs PT $18.3 \mathrm{sec}$ APTT45 sec peripheral smear showed normocytic normochromic with neutrophila with left shift, blood culture was negative and CRP was positive. Flowcytometry showed there is no expression of CD11a/CD18 complex suggestive of LAD-1 deficiency. Gene analysis was sent. Treated with antibiotics cloxacillin, local wound care and regular dressings. Planed for stem cell transplantation. Consent was taken for publication
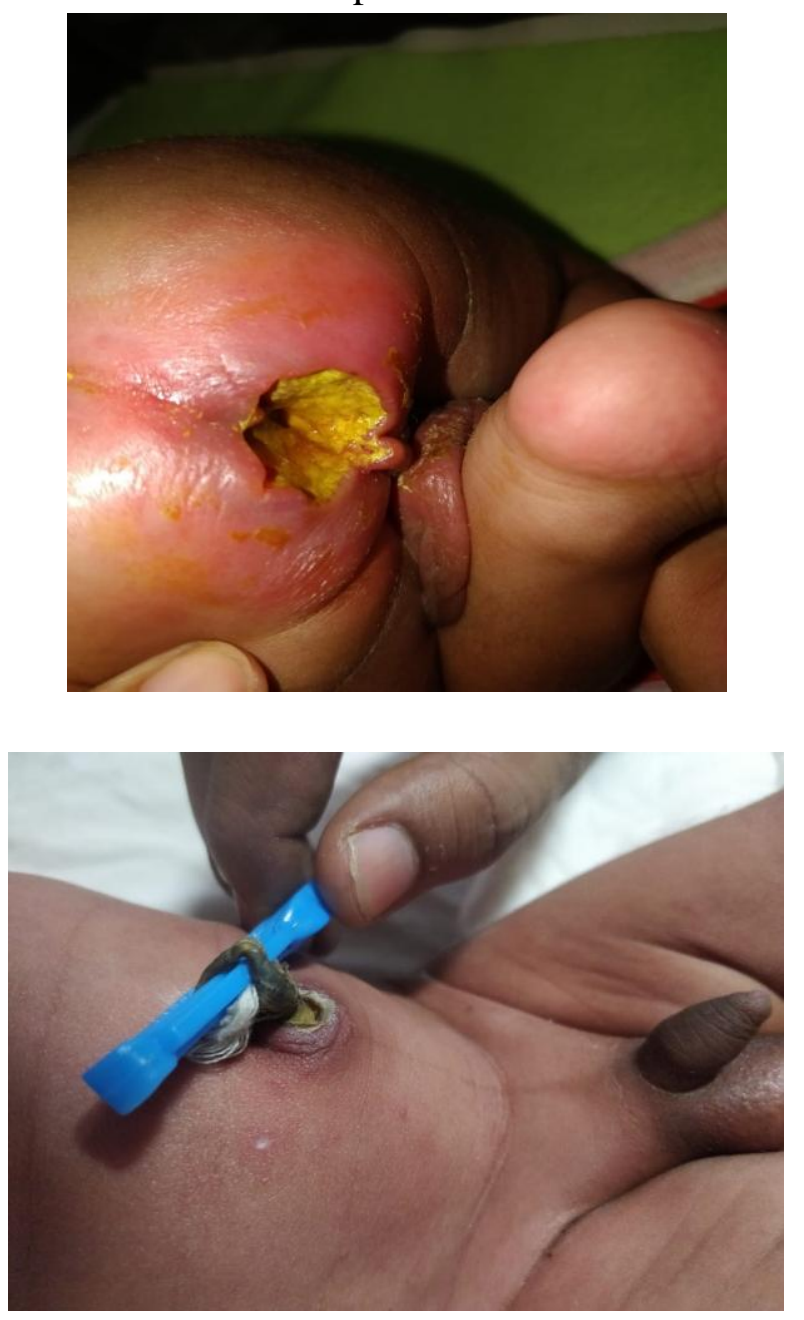

\section{Discussion}

First case of LAD reported in $1970^{(1)}$ Untill now about 400 cases of LAD I were diagnosed worldwide .In india very few cases were reported. LAD2 cases reported mainly from Middle East and Brazil. It is characterized by lack of phagocytic function due to lack of $\beta 2$ integrins molecules CD11 and CD18 which expressed as transmembrane proteins and transmit signals from the extracellular surface to cytoskeletan. They are essential for adhesion and chemotaxis ${ }^{(2,3)}$.LAD has three subtypes type 1 most common due to deficiency of B2 integrin (CD11 and18) which is mapped on $22 \mathrm{q} 22.3$

It also involved in synthesis of proteinsLFA-1, AXB2 and Mac-1/CR3 which are involved in adhesion and chemo taxis .LAD 2 is due to mutation of specific transporter of fucose from the cytoplasm into the Golgi apparatus resulting in lack of fucosilated ligands these patients have Bombay blood group dimorphism and mental retardation. Umbillical cord will fall normally in type 2.LAD 3 is caused by mutation in KINDLIN3 gene which prevent integrens (B1 23 ) activation, it present as severe bleeding as it associated with platelet dysfunction. LAD1 has two varieties mild form where $1-30 \%$ of receptor expression is present and severe form where $<1 \%$ of receptor expression will present ${ }^{(4)}$. Prognosis is worest in severe variety as they succumb severe infections within 2 years ${ }^{(4)}$. Mild variety prognosis is good they will survive into adult hood. Expression of B2 integrins start at 20 wks cordocentisis is useful for diagnosis by cordocentisis. If familial mutation was known, chorionic villous biopsy and amniocentesis will help in establishing diagnosis flowcytometry will help full where DNA analysis was not present. Hemopoitic stem cell transplantation is the curative therapy. ${ }^{(5)}$ Gene therapy is under investigation $^{(6,7)}$. If transplant is accomplished before severe infections have occurred, the prognosis is very good ${ }^{[8]}$. Fucose supplementation usueful in LAD 2 patients for phagocytic functions, neurological functions are irreversible ${ }^{(9)}$ Regular vaccination can be given

\section{Conclusion}

Early suspicion of primary immunodeficiency may improve the prognosis and will give the time to plan stem cell transplantation and prophylactic measures to be taken to prevent sepsis. Any unusual infections in neonates better to think in line of primary immunodeficiency. 


\section{References}

1. Crowley CA, Curnutte JT, Rosin RE, et al. An inherited abnormality of neutrophil adhesion. Its genetic transmission and its association with a missing protein. $\mathrm{N}$ Engl J Med. 1980;302(21):1163-8.

2. Muller WA. Leukocyte-endothelial-cell interactions in leukocyte transmigration and the inflammatory response. Trends Immunol. 2003;24(6):326-33.

3. Tzioni A. Leukocyte adhesion deficiencies: molecular basis, clinical findings, and therapeutic options. Adv Exp Med Biol. 2007;601:51-60.

4. Fischer A, Lisowska-Grospierre B, Anderson DC, Springer TA. Leukocyte adhesion deficiency: molecular basis and functional consequences. Immunodefic Rev. 1988;1(1):39-54.

5. Bauer TR, Hickstein DD. Gene therapy for leukocyte adhesion deficiency. Curr Opin Mol Ther. 2000;2(4):383-8.

6. Mancias C, Infante AJ, Kamani NR. Matched unrelated donor bone marrow transplantation in leukocyte adhesion deficiency. Bone Marrow Transplant. 1999;24(11):1261-3.

7. Farinha NJ, Duval M, Wagner E. Unrelated bone marrow transplantation for leukocyte adhesion deficiency. Bone Marrow Transplant. 2002;30(12):979-81.

8. Hamidieh AA, Poupak Z, Behfar M, Faghihi-Kashani S, Fazlollahi MR, Hosseini AS, et al. Leucocyte adhesion deficiency Type 1: The outcome of reduced intensity conditioning hematopoietic stem cell transplantation. Biol Blood Marrow Transplant. 2015;21(2):S223.

9. Etzioni A, Tonetti M. Fucose supplementation in leukocyte adhesion deficiency type II. Blood. 2000;95 (11):3641-3. 